\title{
Criterios jurídicos para fijar sanciones a los congresistas frente a las omisiones legislativas en Colombia
}

\section{Legal criteria to set sanctions against congressmen for legislative omissions in Colombia}

\author{
Alejandra Grajales López
}

*Abogada, (e) Maestría en Derecho del Comercio Internacional, Coordinadora de semilleros de investigación de la Universidad La Gran Colombia Seccional Armenia. Armenia, Quindío. alejagrales510@gmail.com

Cómo citar: Grajales, A. (2017) Criterios jurídicos para fijar sanciones a los congresistas frente a las omisiones legislativas en Colombia. Inciso, 19 (1): 48-71.

Recibido:07/10/2016 Revisado: 22/02/2017 Aceptado: 20/06/2017

\section{Resumen}

La Corte Constitucional de Colombia mediante sus sentencias manipulativas y exhortativas, ha ido llenando los vacíos inherentes a la regulación legislativa para proteger efectivamente los derechos y garantías establecidas en la Constitución Política. Sin embargo, el verdadero problema de las omisiones legislativas debe ser resuelto desde el seno del Congreso de la República. Así las cosas, es posible evidenciar que no existe normatividad adecuada que genere consecuencias a los miembros del órgano legislativo por incumplimiento de su deber cuando de exhortos emitidos por la Corte Constitucional se trata. En este sentido, se pretende establecer criterios jurídicos que fijen sanciones a los congresistas de la República para garantizar el cumplimiento del deber legislativo cuando se presenten exhortos constitucionales que suplan vacíos propios de las omisiones legislativas. A partir de la distinción del tratamiento jurisprudencial que realiza la Corte Constitucional en los casos de omisiones legislativas relativas y absolutas se identificaron diez sentencias hito a la luz de los exhortos constitucionales que incumplió el poder legislativo. En consecuencia, se pudo determinar la constante vulneración de derechos fundamentales y el auge de incertidumbre jurídica que se presentaba en la sociedad a raíz de la falta de medidas que combatieran dicho problema. Se determinan seis criterios jurídicos, a saber, el axiológico, de priorización, de capacitación legislativa, de garantías constitucionales, positivismo estricto y de participación ciudadana, los cuales permitirán fundamentar una disposición legislativa o constitucional que imponga cualquier tipo de sanción a los miembros del legislativo por incumplimiento del deber, especialmente, cuando de exhortos se refiere.

Palabras clave: Sanción, ley, decisión judicial, parlamento.
The Constitutional Court of Colombia through its manipulative and exhortative sentences has been filling the gaps inherent to legislative regulation, in order to effectively protect the rights and guarantees established in the Political Constitution. However, the real problem of legislative omissions must be solved from within the Congress of the Republic. In this way, it is possible to show that there isn't an adequate legislation able to generate consequences for the members of the legislative body for breach of their duty when they are exhorted (to do it) by the Constitutional Court. In this sense, the intention is to establish legal criteria that establish sanctions to the Congressmen of the Republic to ensure their compliance with the legislative duty when constitutional petitions are submitted to fill voids specific to legislative omissions. From the distinction of jurisprudential treatment made by the Constitutional Court in cases of relative and absolute legislative omissions, ten landmark judgments were identified in light of the constitutional bills that the legislative branch failed to comply with. As a result, it was possible to determine the constant violation of fundamental rights and the heightened legal uncertainty that arose in society as a result of the lack of measures to combat this problem. Six legal criteria are determined: axiological, prioritization, legislative training, constitutional guarantees, strict positivism and citizen participation, which will allow to establish a legislative or constitutional provision that imposes any type of sanction to the members of the legislature for breach of duty, especially when it refers to exhortative sentences.

Key words: Sanction, law, judicial decision, parliament. 


\section{Introducción}

Durante mucho tiempo se ha discutido el trascendental papel que han jugado en los diferentes Estados del mundo, aquellos organismos que se encargan de velar por la supremacía de la norma de normas y la forma en la que sus decisiones han permeado todo el ordenamiento jurídico. De la misma manera, se ha debatido la ineficiencia del Parlamento en cuanto al cumplimiento de su deber legislativo y la ausencia de normas sancionatorias, producto de las omisiones legislativas que cada vez son más frecuentes en nuestro país.

En Colombia, por un lado, adquiere relevancia el derecho constitucional con la creación de la Corte Constitucional en 1991, la cual fue inicialmente concebida con funciones de legislador negativo, pero, en virtud de la ineficacia del Congreso ha asumido un papel positivo ya que sus sentencias son consideradas, actualmente, como fuentes creadoras de derecho. Por otro lado, el Congreso de la República de Colombia es el órgano encargado de expedir la legislación y reglamentación pertinente en todas las materias que afectan al país, sin embargo, ha tomado auge en esta institución el incumplimiento reiterado de su principal deber, lo que genera una constante insatisfacción en la comunidad. A esta falta en el cumplimiento del deber de legislar o la ausencia de normatividad en determinados supuestos de hecho se le conoce como omisiones legislativas.

En el escenario de las omisiones legislativas es menester tomar en consideración que la Corte Constitucional colombiana ha proferido sentencias de carácter exhortativo con la finalidad de no exceder su competencia y sugerir al legislativo cumplir con el deber de regular todos los supuestos de hecho que se puedan presentar en cualquier ámbito. No obstante, ante la desprotección de las personas por la ausencia de norma, ha surgido la polémica en diversos espacios académicos en cuanto a la dicotomía de detectar si el problema radica en la constante extralimitación del poder judicial o en la carencia de medios coercitivos para el cumplimiento eficaz de la función principal de la rama legislativa.

Es evidente que la Corte Constitucional ha intentado garantizar los derechos de las personas que instauran acciones constitucionales, incluso de las personas que no accionan, haciendo extensivos sus fallos, por situaciones que debía haber legislado el órgano correspondiente, lo cual la ha convertido en un verdadero defensor de los derechos y principios fundamentales. sin embargo, desde la teoría de la tridivisión de poderes, planteada por Montesquieu, cada rama del poder público tiene una función que constitucionalmente debe realizar, y es de gran relevancia, no solo determinar las causas del incumplimiento del legislativo, sino generar una posible y efectiva solución, como la imposición de sanciones, que permitan proteger la completa regulación de los derechos garantizados por el Estado social y democrático de derecho colombiano, de lo contrario, se seguirá presentando un estado de inseguridad jurídica para aquellos que se encuentren en una situación no regulada normativamente.

En este orden de ideas, la investigación se contextualizará temporalmente desde el año de 1997, puesto que desdeallíla Corte Constitucional inicia con la apología de los derechos de la sociedad mediante la manipulación de sus sentencias como consecuencia de la ineficacia del Congreso para legislar en diversas problemáticas sociales. Con base en lo anterior, se presentan hasta la actualidad una serie de sentencias hito que intentan suplir los vacíos legislativos y que serán estudiadas con la finalidad de determinar la cantidad de exhortos a través de los cuales la Corte Constitucional le sugiere al Congreso de la República que regule determinada materia, evidenciando mediante esto el incumplimiento y la desprotección que conllevan dichas omisiones. 
La importancia de este trabajo radica en la necesidad de "obligar" al legislador a cumplir con los mandamientos que propiamente le confiere la Constitución y las leyes, ya que al no tener un medio coercitivo que lo impulse a tratar sobre todos los temas, se seguirán presentando exclusiones y violaciones a los derechos e intereses sociales. Esta situación, conllevará a una congestión de la Corte Constitucional, y en consecuencia a que esta ejerza funciones casi legislativas, lo cual sería un atropello a la democracia representativa.

En este sentido, el alcance que tiene la investigación sería, por un lado, establecer criterios jurídicos razonables que permitan dar cumplimiento a los principios de seguridad jurídica, igualdad y protección que tiene el Estado con sus gobernados a través de un medio legal que permita a los miembros del Congreso de la República cumplir con los exhortos de la Corte Constitucional. De otro lado, pretende cooperar con la jurisdicción constitucional en cuanto a la disminución del número de tutelas y demandas de inconstitucionalidad presentadas por la violación constante al derecho de igualdad en los casos de omisiones legislativas, en desarrollo de la idiosincrasia del Estado Social, Democrático y Constitucional de Derecho colombiano.

No obstante, las limitaciones que se presentan en la investigación se derivarían de la desidia e inconveniencia por parte de los miembros del Congreso de la República para legislar sanciones en su contra, pues si bien es cierto que es un deber ético e importante para fortalecer la institución, la ausencia de más de la mitad de los congresistas para votar por los proyectos que sancionan el ausentismo, según el Espectador, evidencia un fuerte desinterés institucional por el tema.

Para determinar estos criterios jurídicos será necesario distinguir, inicialmente, el tratamiento que realiza la Corte Constitucional de Colombia en los casos de omisiones legislativas relativas y absolutas. Con ello será posible identificar, en segundo lugar, las principales sentencias hito a la luz de los exhortos que realiza la Corte Constitucionalal Congreso de la República, para así analizar las consecuencias que se presentan ante la inactividad del Congreso en los casos de omisiones legislativas por ausencia de medidas sancionatorias. Esto permite establecer los lineamientos para formular sanciones jurídicas aplicables a los congresistas en los casos de incumplimiento de los exhortos realizados por la Corte Constitucional.

\section{Metodología}

Esta investigación presenta un enfoque cualitativo, con una orientación jurídica de carácter analítico y propositivo, a través de una técnica de análisis documental en la que, inicialmente se recopilará y realizará una lectura de la principal normatividad nacional, doctrina y tipología de sentencias constitucionales manipulativas, exhortativas y de inconstitucionalidad por omisión emitidas a partir del año de 1997 hasta el 2017, las cuales han sido seleccionadas por su relevancia e impacto en la sociedad. En este sentido, se pretende evidenciar, a partir de 10 sentencias hito, el comportamiento del Congreso de la República ante una omisión legislativa relevante. Con lo anterior, se analizaron los diferentes temas, entre ellos, matrimonio entre parejas homosexuales, eutanasia, aborto, alquiler de vientres, entre otros, en los que actúa la Corte Constitucional para suplir la inactividad del Congreso de Colombia y para garantizar los derechos e intereses de la sociedad. A partir de lo anterior, se identifica a nivel nacional, múltiples normatividades sancionatorias que se aplican a los miembros del órgano legislativo y se realiza un análisis sobre las principales opciones jurídicamente viables para contrarrestar las consecuencias derivadas de las omisiones legislativas. Finalmente, para 
dar cumplimiento a los objetivos, se proponen criterios jurídicos que permitan solucionar el problema inicialmente planteado.

\section{Nociones de omisiones legislativas}

Siguiendo la corriente de la Corte Constitucional, esta define la omisión legislativa como:

[...] Dichas omisiones, entonces, se identifican con la "no acción" o falta de actividad del legislador en el cumplimiento de la obligación de legislar que le impone expresamente el Constituyente. Para que se pueda hablar de omisión legislativa, es requisito indispensable que en la Carta exista una norma expresa que contemple el deber de expedir la ley que desarrolle las normas constitucionales y el legislador lo incumpla, pues sin deber no puede haber omisión [...]. (Sentencia C-543/96, p. 7)

En efecto, se afirma que existe una omisión legislativa, cuando el legislador no cumple un deber de acción expresamente señalado por el Constituyente. Igualmente señala la Corte que las omisiones legislativas se producen en los siguientes casos:

(i) Cuando no produce ningún precepto encaminado a ejecutar el deber concreto que le ha impuesto la Constitución. (ii) Cuando en cumplimiento del deber impuesto por la Constitución, favorece a ciertos grupos, perjudicando a otros. (iii) Cuando en desarrollo de ese mismo deber, el legislador en forma expresa o tácita, excluye a un grupo de ciudadanos de los beneficios que otorga al resto. (iv) cuando el legislador al regular o construir una institución omite una condición o un ingrediente que, de acuerdo con la Constitución, sería exigencia esencial para armonizar con ella . (Sentencia C-543/96, p.7)

La primera de las anteriores situaciones corresponde a una omisión legislativa absoluta y las demás configuran formas de omisión legislativa relativa, donde se desconoce el derecho a la igualdad o cualquier otro derecho fundamental permitiéndole a la Corte Constitucional pronunciarse al respecto.

En este sentido, en los casos de omisiones legislativas absolutas existe una ausencia total de norma que debería regular una situación jurídica establecida constitucionalmente, lo cual solo permite que la única forma de corregir dicha omisión sea a través del exhorto o "llamado" que hace la Corte Constitucional al Congreso como encargado, por excelencia, de hacer las leyes. Es claro que en los casos de deficiencia legislativa total o absoluta, el Tribunal Constitucional carece de competencia por no tener una norma para llevar a cabo la confrontación con la Constitución Política, por lo tanto, en la mayoría de casos se declara inhibida.

De otro lado, las omisiones legislativas relativasson aquellas donde el legislador, al expedir una norma, excluye ciertos supuestos de hecho o grupos de personas, generando un estado de inseguridad jurídica para las mismas al no estar cobijadas por una normatividad que regule su caso. Por lo tanto, "habrá omisión relativa toda vez que en el cumplimiento del mandato constitucional, el órgano legislativo encargado de efectivizarlo quiebre - en forma no intencional, pero produciendo un resultado discriminatorio y/o arbitrario- el principio de igualdad.” (Rangel, 2008).

\section{Tratamiento jurisprudencial de las omisiones legislativas}

Para efectos de la investigación, solo se toman en cuenta dos de las vertientes o clasificaciones de las modulaciones de las sentencias constitucionales en ejercicio del control de constitucionalidad, puesto que son las más utilizadas por la Corte Constitucional en sus decisiones para la protección de aquellos que no 
se encuentran inmersos en una situación jurídica normativa; las sentencias manipulativas y las exhortativas.

Las sentencias manipulativas, según la doctrina, tienen la finalidad de garantizar el principio de seguridad jurídica, puesto que a través de la "manipulación" de la norma evitan la creación de un vacío legislativo generador de mayor inconstitucionalidad sin expulsar o dejar sin vigencia la misma.

En esta clase de sentencias, autores como Olano (2004, p.7), han afirmado que la Corte se presenta como un verdadero legislador positivo, ya que incorpora al ordenamiento jurídico nuevos contenidos normativos, eliminando apartes de la norma jurídica bajo su cuidado o de una norma elaborada a través de la interpretación de una o varias disposiciones normativas, de manera que cambia el significado del enunciado legal demandado.

De otro lado, Garay Herazo, expresa que las sentencias manipulativas como categoría general agrupan ese conjunto de decisiones distintas a las de exequibilidad o inexequibilidad pura. Entre ellas podemos encontrar tres grupos: i) el de las sentencias interpretativas, ii) el de las sentencias aditivas y, iii) el de las sentencias sustitutivas (Garay, 2014, p.79).

El Dr. Nogueira (2009, p.28) señala que existen sentencias interpretativas estimativas o de acogimiento cuando se consideran inconstitucionales ciertas interpretaciones del enunciado normativo, es decir, determinadas normas que surgen de la interpretación considerada inconstitucional, siendo estas interpretaciones expulsadas del ordenamiento jurídico, aún cuando se mantenga inalterado el enunciado normativo del cual surgen dichas interpretaciones. Existe un gran número de sentencias interpretativas que emite la Corte Constitucional, tales como la C-621 de 2001,
C-545 de 2008, C- 822 de 2005, C-619 de 2011, entre otras.

Las sentencias aditivas o integradoras son aquellas que declaran la ilegitimidad constitucional de la previsión omitida que debía ser prevista por la ley (omisión legislativa relativa o vulneración del principio de igualdad) para que esta fuera constitucional. Por lo tanto, el juez constitucional, mediante el empleo de este tipo de decisión, garantiza la efectividad de los principios, derechos y deberes consagrados en la Constitución en su artículo segundo. En estas sentencias, la Corte no anula la disposición acusada, pero le agrega un contenido que la hace constitucional. Se incorpora un elemento nuevo al enunciado normativo, extendiendo la norma para que asuma un supuesto de hecho no contemplado en sus inicios.

Por último, las sentencias sustitutivas, que no son comunes en el ordenamiento jurídico colombiano, hacen referencia a aquellos eventos donde la Corte o el Tribunal Constitucional expulsan del ordenamiento jurídico una disposición y sustituye el vacío normativo por una regulación específica que es directamente constitucional. Es una combinación de una sentencia de inconstitucionalidad y una integradora, ya que anula un precepto y lo llena por medio de un nuevo mandato que la sentencia adiciona o integra. (Olano, 2004, p.580). Uno de los ejemplos más cercanos a esta modalidad fue cuando la Corte Constitucional profirió la sentencia C 113 de 1993 con Magistrado Ponente Jorge Arango Mejía, en la cual declaró la inexequibilidad de ciertos artículos del Decreto 2067 de 1991, limitando los efectos de los fallos de la Corte.

Las sentencias exhortativas o apelativas según Olano (2004, p.581) son el resultado de la constatación de situaciones aún constitucionales, donde se hace una apelación al legislador para alterar la situación dentro de un plazo 
expresamente determinado por la Corte, tal y como lo establece la postura de la jurisprudencia constitucional:

La jurisprudencia constitucional ha señalado, desde esta perspectiva de análisis, que frente a la competencia legislativa para aprobar las leyes, el instrumento con que cuenta la Corte ante la concurrencia de vacíos legislativos absolutos, que ponen en riesgo derechos constitucionales, es la figura del exhorto. Esta fórmula está circunscrita a la apelación al Congreso para que ejerza sus competencias sobre determinado asunto. (Auto 078/2013, p.10.)

Con base en lo anterior cabe mencionar que en Colombia se aplica la figura del exhorto al Congreso de la República, en primer lugar, cuando se presenta la figura de la omisión legislativa absoluta en la cual la Corte no puede interferir, puesto que no existe una norma que regule el tema, por lo tanto, le corresponde al legislador suplir el vacío; o en los fallos de inexequibilidad diferida, que son aquellos donde se establece un plazo para regular una norma, como fue el caso del derecho fundamental de petición (Corte Constitucional, 818-2011, p.72).

La investigación se enfoca en el análisis del primer exhorto en donde la Corte sugiere al Congreso de la República que regule un tema específico con la finalidad de conservar el sistema de pesos y contrapesos de las ramas del poder público y de asegurar que se cumpla con el principio democrático que pregona nuestro Estado social de derecho.

\section{Principales sentencias hito}

A continuación, se relacionan en orden cronológico diez sentencias hito, desde 1997 hasta el 2017, que tratan temas de trascendencia nacional, en los cuales la Corte Constitucional, a través de la modulación de sus sentencias, resolvió o se inhibió en torno a los derechos de los accionantes.
Cabe aclarar, que la intención principal de este cuadro es demostrar que el Congreso de la República incumple constantemente los exhortos que le son dados, no solo en caso de omisiones legislativas, sino en cualquier situación donde la Corte Constitucional no pueda pronunciarse por falta de competencia.

Cabe recordar que para configurar una omisión legislativa relativa y la Corte Constitucional poder pronunciarse a través de la modulación de sus sentencias, es indispensable que exista una norma sobre la cual sea posible comparar una disposición constitucional, dicha regulación debe ser discriminatoria, injustificada y carecer del principio de razón suficiente, no obstante, el hecho que exista una ley o disposición normativa no es determinante para catalogarla como omisión relativa, ya que, si la omisión no emerge de dicho precepto, así exista un artículo de la Constitución que se vea afectado, el Tribunal Constitucional no podrá pronunciarse por ser una actividad que le compete al legislativo. Por lo tanto, cuando suceda dicha situación se configurará en la investigación como una omisión legislativa absoluta.

A través del presente cuadro se resumirán los aspectos más relevantes para la investigación de cada una de las jurisprudencias examinadas:

1) Sentencia C- 239 del año de 1997 con Magistrado Ponente el Dr. Carlos Gaviria Díaz trata el polémico tema del homicidio por piedad- eutanasia. La omisión absoluta consistía en que el consentimiento de la víctima era una condición necesaria para configurar ciertos tipos penales y las modalidades en que se cometían, sin embargo, en relación con el homicidio por piedad, no existía ninguna disposición penal sobre el consentimiento del sujeto pasivo del hecho, por lo tanto, en caso de que se presentara la voluntad del paciente a morir a causa de una enfermedad, el servicio médico no podía acceder a su petición porque estarían incurriendo en un delito. 
La Corte decidió declarar exequible el artículo 326 del decreto 100 de 1980 (Código Penal), con la advertencia de que en el caso de los enfermos terminales en que concurra la voluntad libre del sujeto pasivo del acto, no podrá derivarse responsabilidad para el médico autor, pues la conducta está justificada, igualmente exhortar al Congreso para que en el tiempo más breve posible, y conforme a los principios constitucionales y a elementales consideraciones de humanidad, regulara el tema de la muerte digna.

En lo que respecta a la regulación, fue el Ministerio de Salud y Protección Social, mediante la Resolución 1216 de 2015, la que estableció los requisitos para la organización y funcionamiento de los Comités que hicieran efectivo el derecho a morir con dignidad en los términos de la sentencia T-970 de 2014 y de la sentencia C-239 de 1997. El tiempo transcurrido para efectuarse una regulación fue de 18 años.

2) Sentencia C 355 de 2006 con Magistrados Ponentes el Dr. Jaime Araújo Rentería y la Dra. Clara Inés Vargas Hernandez. Ésta sentencia trata el tema del aborto en Colombia, los demandantes fueron Mónica del Pilar Roa López, Pablo Jaramillo Valencia, Marcela Abadía Cubillos, Juana Dávila Sáenz y Laura Porras Santillana. La omisión relativa consistía en que existía una falta de regulación que permitiera ciertos presupuestos para la interrupción voluntaria del embarazo.

Por lo anterior, la Corte Constitucional, en este caso emite una sentencia interpretativa donde declara exequible el artículo 122 de la Ley 599 de 2000, en el entendido que no se incurre en delito de aborto, cuando con la voluntad de la mujer, la interrupción del embarazo se produzca en los casos anteriormente señalados, por lo tanto, no fue necesario expedir normatividad, puesto que la modulación de la sentencia interpretó el alcance de la norma. El tiempo transcurrido para efectuarse una regulación fue inmediato.
3) Sentencia T 968 de 2009, el discutible caso del alquiler de vientres, con Magistrado Ponente la Dra. María Victoria Calle Correa. sentencia T 968 de 2009, el discutible caso del alquiler de vientres, con Magistrado Ponente la Dra. María Victoria Calle Correa. La omisión es de carácter absoluto y es incompetente la Corte para regular esta clase de situaciones, sin embargo, establece unos parámetros básicos o lineamientos para formular una norma la cual garantice la protección de quienes realizan el procedimiento. De otro lado, el Congreso de la República radicó en la Cámara de Representantes el Proyecto de ley 202 de 2016 sobre los presupuestos para la maternidad subrogada en Colombia. El tiempo transcurrido para hablar o efectuarse una posible regulación ha sido de 8 años.

4) Sentencia C 442 de 2009 con magistrado ponente el Dr. Humberto Sierra Porto que se pronunció acerca de la responsabilidad de los medios de comunicación. La Corte Constitucional encuentra que existe una carencia en el establecimiento normativo de un régimen de responsabilidades de los medios de comunicación respecto de los(as) menores de 18 años, ya que no existen medidas a favor de niños y niñas que sean eficaces, en este sentido, se configura una omisión de carácter absoluto. Con referencia a lo anterior, la Corte Constitucional decide exhortar al Congreso de la República para que regule en el menor tiempo posible y de manera integral, la forma en que se determina la responsabilidad de los medios de comunicación por el incumplimiento de las abstenciones contenidas en los numerales 5, 6, 7 y 8 del artículo 47 del Código de Infancia y Adolescencia, y las sanciones que ello acarrea.

Hasta el momento no existe una ley específica que regule el tema, sin embargo, el Ministerio de Tecnología de la información y Telecomunicaciones en desarrollo del artículo 47 de la ley 1098 de 2010 expidió la Resolución 415 
de 2010 la cual en su artículo 24 estipula que el Ministerio ejercerá las facultades de inspección, vigilancia y control frente a los proveedores del servicio de radiodifusión sonora para verificar el cumplimiento de lo previsto en el mencionado artículo 47, como garantía de los derechos de los niños, niñas y adolescentes.

5) Sentencia C 577 de 2011 con Magistrado Ponente el Gabriel Eduardo Mendoza Martelo los accionantes Carlos Andrés Echeverry Restrepo, Marcela Sánchez Buitrago, Rodrigo Uprimny Yepes, Luz María Sánchez Duque, Diana Esther Guzmán Rodríguez, César Rodríguez Garavito, Mauricio Noguera Rojas, Felipe Montoya, Felipe Arias Ospina, Juan Miguel Eslava Lozzi y Juliana Emilia Galindo Villarreal presentan demanda de inconstitucionalidad en contra de las expresiones "entre un hombre y una mujer" contenidas en el artículo 113 del Código Civil que trata sobre la figura del matrimonio. En la actualidad, existe regulación en torno al matrimonio entre parejas heterosexuales, sin embargo no se ha creado una legislación que regule la misma figura para las parejas del mismo sexo por lo tanto, se configura una omisión absoluta.

Con base en dichos presupuestos la Corte Constitucional decide exhortar al Congreso de la República para que antes del 20 de junio de 2013 legisle, de manera sistemática y organizada, sobre los derechos de las parejas del mismo sexo con la finalidad de eliminar el déficit de protección.

Para solucionar dicha problemática, se radicaron proyectos de ley ante el Congreso que fueron rechazados o negados, por lo que, le correspondió a la Corte Constitucional a través de la Sentencia SU 214 de 2016 aprobar la posibilidad de contraer matrimonio entre parejas del mismo sexo, casi 5 años después del exhorto incumplido.

6) Sentencia T 129 de 2011 con Magistrado Ponente el Dr. Jorge Iván Palacio Palacio se habla de una omisión legislativa en el campo de la consulta previa de las comunidades indígenas. Según la Corte es necesario y urgente que se consolide a nivel normativo y real los derechos de las comunidades étnicas del país para ello deberán crear e implementar herramientas que contribuyan de forma efectiva a la consecución del consentimiento libre, previo e informado según las costumbres y tradiciones del grupo étnico determinado, por lo que, se configura una omisión de tipo absoluto.

Conforme a lo anterior, la Corte Constitucional decide exhortar al Congreso y a la Presidencia de la República para que, en ejercicio de sus competencias constitucionales y legales, regulen y a través de sus organismos competentes materialicen el derecho fundamental a la consulta previa y el consentimiento, libre, previo e informado de los grupos étnicos que hacen parte de la Nación.

En su época, el Ministerio del Interior expidió el Decreto número 1320 de 1998 el cual reglamentó la consulta previa en las comunidades indígenas, Convenio 107 Y 169 de la Organización Internacional del Trabajo (OIT), aproximadamente 6 años para regular el tema.

7) Sentencia C 359 de 2013 con Magistrado Ponente el Dr. Jorge Iván Palacio Palacio trata el tema de la vivienda digna para la población gitana. Se presenta una omisión legislativa relativa por la existencia de un tratamiento discriminatorio al interior de los grupos étnicos y culturales de la Nación, específicamente al excluir de las normas acusadas a la población gitana y a los raizales, por lo tanto, al existir un déficit de protección de manera general de los derechos fundamentales de la población Rrom o Gitana y específicamente en relación con el derecho de vivienda.

En este contexto, La Corte Constitucional decidió declarar exequibles los artículos 13 
y 28, parciales, de la Ley 1537 de 2012, en el entendido de que los criterios de priorización para acceder a los proyectos de vivienda de interés social y de interés prioritario, también deberán tener en cuenta al pueblo Rrom o Gitano y a las comunidades raizales, como grupos étnicos y culturales de la Nación. Teniendo en cuenta que era una sentencia de modulación integrativa, no es necesario expedir normatividad puesto que su adopción es inmediata.

8) Sentencia T 099 de 2015, con Magistrada Ponente la Dra. Gloria Stella Ortiz Delgado, que regula el tema de identidad de género transexual. No existe normatividad específica que proteja las personas que cambian de género e identidad, ni mecanismos de modificación de los registros oficiales que validen dicho cambio, y tampoco un protocolo de admisión al servicio militar voluntario de las personas transexuales, por lo cual ésta población afronta múltiples barreras que impiden la plena realización de sus derechos fundamentales.

Con base en lo anterior, la Corte exhorta al Congreso de la República, para que, en el menor tiempo posible, promulgue una Ley de Identidad de Género que proteja los derechos fundamentales de las mujeres y hombres transexuales, con la consideración, entre otros, de los fundamentos de esta providencia.

Hasta el momento no se ha expedido normatividad alguna, la Corte Constitucional mediante su exhorto es clara en especificar el enfoque con el cual el Congreso de la República debe regular un tema que cada vez es más frecuente.

9) Sentencia C 683 de 2015, adopción por parejas del mismo sexo, con magistrado ponente Jorge Iván Palacio Palacio. El problema jurídico de la Corte consistión en resolver, desde un enfoque constitucional, "si las normas que regulan el régimen legal de adopción en Colombia, al excluir a las parejas del mismo sexo de la posibilidad de participar en procesos de adopción, vulneraban el principio del interés superior del menor, representado en su derecho a tener una familia para garantizar su desarrollo armónico e integral (art. 44 CP)" (Corte Constitucional, 683/2015, p. 56) .

En este sentido resuelve declarar exequibles las expresiones impugnadas de los artículos 64, 66 y 68 (numerales $3^{\circ}$ y $5^{\circ}$ ) de la Ley 1098 de 2006 , "por la cual se expide el Código de la Infancia y la Adolescencia", así como del artículo $1^{\circ}$ (parcial) de la Ley 54 de 1990, "por la cual se definen las uniones maritales de hecho y régimen patrimonial entre compañeros permanentes", bajo el entendido que, en virtud del interés superior del menor, dentro de su ámbito de aplicación están comprendidas también las parejas del mismo sexo que conforman una familia.

10) Sentencia C-005 de 2017, estabilidad laboral reforzada a la pareja de mujer embarazada o lactante no trabajadora, con Magistrado Ponente Luis Ernesto Vargas Silva. Manifiesta la Corte Constiucional que se presenta una omisión legislativa relativa que recae sobre los enunciados normativos que regulan: (i) la prohibición de despedir a una trabajadora por motivo de embarazo o lactancia (Numeral 1 del artículo 239 C.S.T.); (ii) el requerimiento de autorización del Inspector del Trabajo, o en su defecto del Alcalde Municipal para poder despedir a una trabajadora durante el período de embarazo o los tres meses posteriores al parto.

En consecuencia, "para remediar la inconstitucionalidad la Corte declarará la exequibilidad condicionada del numeral primero del artículo 239 del Código Sustantivo del Trabajo y del numeral primero del artículo 240 del mismo estatuto, en el entendido que la prohibición de despido y la exigencia de permiso para llevarlo a cabo, se extienden al(la) trabajador(a) que tenga la condición de cónyuge, 
compañero permanente o pareja de la mujer en período de embarazo o lactancia, que sea beneficiaria de aquel(la)" (Corte Constitucional, C 005/2017, p. 37).

Conforme a lo anterior, es menester resaltar que, en la mayoría de los casos, el Congreso de la República no ha cumplido con su deber de legislar en algunas de las materias que han generado polémica y son de trascendencia para gran parte de la población nacional, solo en los asuntos en que la Corte Constitucional modula sus sentencias se genera un cumplimiento y adopción inmediata, ya sea de la interpretación o integración de la norma; sin embargo, para legislar sobre un tema que la Corte ha exhortado, transcurre un amplio término hasta que otro organismo o la misma corporación expida una regulación pertinente.

\section{Consecuencias derivadas de la ausencia de medidas sancionatorias}

Para establecer la normatividad existente sobre las sanciones que se imponen a los congresistas de la República, se enuncian a continuación diversas reglamentaciones que contienen algunos controles y límites a las potestades de los parlamentarios:

1. La Constitución Política de Colombia contiene las actuaciones generales que se encuentran prohibidas para los miembros del Congreso de la República, las cuales tienen la finalidad de garantizar los principios de transparencia y democracia plasmados en la norma fundamental . El congresista tiene el deber de dedicarse a su actividad parlamentaria y, por lo tanto, cualquier conducta irregular que vulnere los intereses, deberes o derechos de terceros, están prohibidas constitucionalmente y otorgan algún tipo de sanción o pena por incurrir en la tipificación de ciertos delitos contra la administración pública que se encuentran en otras normas del ordenamiento jurídico. Así mismo establece las funciones que le corresponden al Congreso y las situaciones por las cuales una persona no podría aspirar al cargo de congresista por no cumplir algún requisito específico para poder ejercer el poder de representación en el cuerpo colegiado.

La norma fundamental también incluye la figura de la pérdida de investidura. De acuerdo con el artículo 183, cuando se incurre en alguna de las causales allí establecidas, es posible iniciar a los congresistas un juicio de responsabilidad ante la Sala Contenciosa Administrativa del Consejo de Estado, a petición de la mesa directiva de la Cámara correspondiente o de cualquier ciudadano, en un término no mayor de veinte días hábiles contados a partir de la fecha de la solicitud. Por ser esta una de las sanciones más importantes para los congresistas, vale la pena destacar dos aspectos. En primer lugar, en caso de que sí haya faltado a su código de responsabilidad y ética como congresista, transgrediendo el principio de moralidad administrativa de la función pública, al realizar alguna de estas conductas, se declara la pérdida de investidura, la cual es una sanción de carácter político y jurídico que genera la "muerte política" o futuras candidaturas a cargos de elección popular del sentenciado. Y en segundo lugar, en lo que concierne a la sanción penal, su conocimiento es competencia privativa de la Corte Suprema de Justicia por la calidad del funcionario indiciado. No obstante, la pérdida de investidura en Colombia es una de las sanciones menos utilizadas o más fallidas.

Así las cosas, los congresistas y diferentes magistrados de las altas cortes han solicitado una reforma a esta figura, con la finalidad de que la sanción se aplique de manera gradual y no abrupta como está en la Constitución y normas concordantes, aunque si no se invoca o solicita en la actualidad, de forma paulatina sería menos exigente su aplicación y cumplimiento. 
2. Reformas constitucionales: El Acto Legislativo 01 de 2009 "Por el cual se modifica el artículo 107 de la Constitución Política de Colombia" señala que los partidos y movimientos políticos también sean sujetos de responsabilidad y de sanciones por su mal funcionamiento, es así como la reforma introduce un régimen de responsabilidad cuando se avalen candidatos que hayan sido condenados durante el cargo, o por ir en contravía de las normas, valores y principios que los rigen.

3. Leyes: La Ley 5 de 1992 "Por la cual se expide el Reglamento del Congreso; el Senado y la Cámara de Representantes" cita aspectos importantes a tener en cuenta tales como las inhabilidades, incompatibilidades, faltas, sanciones y la ya mencionada pérdida de investidura. En la norma se plasman las causales por las cuales una persona se considera impedida o inhábil para aspirar a ser congresista. En dicha normatividad, no se observa que se haga énfasis en una sanción por incumplimiento del deber de legislar en casos de exhorto constitucional, solo el artículo 269 reitera las faltas de los congresistas que se resumen en tres:

1. El desconocimiento a los deberes que impone este Reglamento.

2. El cometer actos de desorden e irrespeto en el recinto de sesiones.

3. No presentar las ponencias en los plazos señalados, salvo excusa legítima.

De igual forma, la inasistencia de los Congresistas a las sesiones, sin excusa válida, está consagrada como una falta en el artículo 271, la cual genera como consecuencia, por un lado, no percibir los salarios y prestaciones correspondientes, y por otro, si hubiere lugar, la pérdida de investidura.

Es evidente que esta reglamentación es bastante antigua $\mathrm{y}$ ha tenido modificaciones, aunque se han presentado diferentes propuestas para renovarla, han resultado fallidas, ya que uno de los principales obstáculos son los mismos congresistas que archivan los proyectos o votan en contra de crear sanciones más severas y estrictas para el cumplimiento del reglamento.

4. La Ley 734 de 2002, Código Disciplinario Único, fija en su artículo 35 las prohibiciones de los servidores públicos, entre ellas, y en la que más se hace énfasis, el incumplimiento de los deberes o abuso de los derechos o extralimitación de las funciones contenidas en la Constitución, los tratados internacionales ratificados por el Congreso, las leyes y demás normatividad.

\section{Proyectos de ley}

El Congreso de la República presentó el proyecto de ley orgánica No. 200 de 2013 mediante el cual pretendía expedir el "Código de Ética y Disciplinario del Congresista" que contenía todo lo relacionado con la responsabilidad y las sanciones en caso de incurrir en una conducta indecorosa, irregular o inmoral en ejercicio de su función pública o con ocasión a la misma. Finalmente, y según la página de la Secretaría del Senado, este proyecto solo pasó por primer debate y quedó archivado al poco tiempo de ser presentado, evidenciando el poco interés que tienen los miembros del Congreso de modificar o renovar su reglamento interno, sobre todo en cuanto a sanciones se refiere. Así mismo, el Centro Democrático propuso en agosto de 2015 una iniciativa que buscaba "endurecer las sanciones y fortalecer los procesos para su aplicación, con el fin de combatir el ausentismo de los congresistas y funcionarios citados a sesiones plenarias y comisiones" (Centro Democrático, 2015), la cual según informa el periódico el País en junio de 2016 se hundió porque no hubo quórum para ser votado. (Bautista, 2014) 


\section{Disertaciones derivadas de la ausencia de medidas sancionatorias}

Teniendo en cuenta la normatividad relacionada en los acápites anteriores, es posible determinar que no existen medidas para aquellos casos donde se presenta un incumplimiento por exhortos proferidos por la Corte Constitucional o por déficit en el deber legislativo, lo que conlleva a que se generen consecuencias jurídicas $\mathrm{y}$ sociales a raíz de la ausencia de una regulación sancionatoria estricta para los congresistas. A continuación se relacionarán las principales:

1. Vulneración de derechos fundamentales: al presentarse la ausencia de una medida estricta que implique una consecuencia, sea de carácter económico o jurídico que le exija al congresista cumplir con su deber de asistir a las sesiones del congreso a debatir y legislar, se presentan vacíos normativos que afectan los derechos de los miembros de la sociedad. Es así como a través de las diferentes demandas de inconstitucionalidad presentadas ante la Corte Constitucional, se refleja un fuerte debate jurídico por parte de los accionantes al intentar buscar protección de sus derechos fundamentales por otras vías legales, por ejemplo mediante las acciones constitucionales tales como la acción de tutela, cumplimiento, popular, de grupo, habeas corpus, habeas data e incluso el derecho de petición, con la finalidad de evidenciar ante el Congreso de la República su situación jurídica, la cual, como lo ordena la norma fundamental, merece una regulación.

Ahora bien, cabe mencionar que a raíz de dichas omisiones, sin duda alguna, se están vulnerando derechos fundamentales de las personas, puesto que el Congreso, al no realizar bien su deber de hacer las leyes, permite que se presenten las omisiones legislativas, las cuales si no son desarrolladas por el único que ente competente para ello, desencadenan en un estado de incertidumbre jurídica que transgrede uno de los principales pilares del Estado de Social de derecho: la igualdad.

2. Conflicto Socio-Jurídico: en este punto es indispensable traer a colación un componente que puede resultar subjetivo en cuanto a su análisis, pero que influye inevitablemente en la falta de regulación de medidas sancionatorias para los miembros del Congreso de la República, este es la corrupción.

Para iniciar, el término corrupción es definido por la Corporación Transparencia por Colombia como "el abuso de posiciones, poder o confianza, para beneficio particular en detrimento del interés colectivo, realizado a través de ofrecer o solicitar, entregar o recibir, bienes en dinero o en especie, cambio de acciones, decisiones u omisiones" (Corporación Transparencia por Colombia, 2009, p.4). Así las cosas, el concepto de corrupción es tan amplio como tantas aristas se quieran explorar, sin embargo, es claro que dicho comportamiento por parte de los servidores públicos causa detrimento en el interés colectivo. Haciendo un símil con la actual situación del Congreso de la República, es posible evidenciar que se presentan variedad de casos de corrupción por parte de algunos de sus miembros, no sólo en los aspectos políticos sino en lo que a la toma de decisiones respecta, es así como se han presentado diferentes proyectos de ley por parte de algunos senadores o representantes a la Cámara que pretenden establecer multas o sanciones por incumplimiento o inasistencia a los debates pero que son archivados posteriormente.

3. Sistema Jurídico: Los sistemas jurídicos son el conjunto de normas jurídicas objetivas e instituciones gubernamentales que están vigentes en un país y que regulan conforme a derecho la conducta de las personas en sociedad. Para García Máynez, es el conjunto de normas jurídicas objetivas que están en vigor en determinado lugar y época, y que el estado estableció o creó con objeto de regular la 
conducta o el comportamiento humano (García, 1989).

Existen diferentes tipos de familias jurídicas entre ellas la de Derecho Continental, la anglosajona o Common Law, Derecho Religioso, Derecho Consuetudinario y los sistemas híbridos de Derecho Civil y anglosajón., En Colombia, se presenta un sistema combinado por no decir "mixto", puesto que, predomina la codificación y legislación, como es lo normal del sistema continental que hemos aplicado, sin embargo, y con el paso de los años, el activismo judicial y la importancia de sus decisiones ha aumentado a tal grado que se le ha dado un valor tan alto a la jurisprudencia que el término "criterio auxiliar" establecido en el artículo 230 de la Constitución Política ya ha sido interpretado de manera muy similar al sistema anglosajón en cuanto a la obligatoriedad y vinculación de la ratio decidendi. Con base en lo anterior, se podría plantear que el cambio de sistema permitiría disminuir el número de congresistas y catalogar la jurisprudencia como la fuente principal de derecho en cuanto interpreta y determina el alcance de los preceptos constitucionales protegiendo y regulando mejor las situaciones sociales, pero, no sería lo más conveniente, puesto que en nuestro país existe demasiada normatividad, por no especificar, que por cada situación hay una norma y una jurisprudencia, lo cual es un doble trabajo para el órgano legislativo y judicial. Por lo tanto, si cada rama del poder público cumpliera con sus funciones tendría que adoptar medidas o planes de acción que permitieran impulsar la actividad legislativa con base en algunos parámetros jurisprudenciales y en caso excepcional las altas Cortes sobrepasar su competencia para proteger jurídicamente los intereses sociales.

4. Inseguridad Jurídica: Como se ha dicho con anterioridad, cuando una persona se encuentra ante la presencia de omisiones legislativas en determinada materia, se presenta un estado de inseguridad jurídica.

Para determinar mejor el alcance de dicho presupuesto, es necesario comprender en primer lugar lo relativo a la seguridad jurídica según la Sentencia T 502 de 2002:

La seguridad jurídica es un principio central en los ordenamientos jurídicos occidentales. La Corte ha señalado que este principio ostenta rango constitucional // En materia de competencias, la seguridad jurídica opera en una doble dimensión. De una parte, estabiliza las competencias de la administración, el legislador o los jueces. Por otra parte, otorga certeza sobre el momento en el cual ocurrirá la solución del asunto sometido a consideración del Estado. // Al considerarse en el ámbito de la certeza y estabilidad jurídica (seguridad jurídica), la existencia de precisos términos para que la administración o el juez adopten decisiones y el principio de conocimiento de las normas aplicables al caso concreto, se sigue que dichos términos fijan condiciones de estabilización respecto de los cambios normativos (...)" (Corte Constitucional, 250/2012)

Teniendo en cuenta el anterior extracto jurisprudencial, este es un principio fundamental derivado del preámbulo y de los artículos 1,2,4,5 y 6 de la Constitución Política, que soporta las decisiones judiciales y así mismo la competencia de órganos, como el Congreso de la República, para expedir su normatividad y cumplir con sus funciones.

El Congreso de la República se conforma por 268 miembros, los cuales son los encargados de muchas funciones, pero la principal, es expedir la normatividad; se encuentra dividido por comisiones que regulan diferentes temas lo que permite una mejor organización; pero, en la gran mayoría de casos no se alcanza un consenso para regular temas trascendentales producto de omisiones legislativas. 
Adicional a esto, no sólo el Congreso debe garantizar la aplicación de dicho principio, también los órganos de control tanto internos (gestión o disciplinario), como externos (procuraduría o contraloría), deben realizar una vigilancia y exigencia para su cumplimiento, incluso, el mismo control social presiona para que se expida la norma en casos de trascendencia nacional, no obstante, la inoperancia de ambos controles ha permito que este principio, que es uno de los que más soporta la actividad legislativa y judicial, sea poco efectivo, provocando la situación de inconformidad, desconfianza, incertidumbre e irrespeto en contra de los cuerpos colegiados que actualmente tiene la sociedad, por su constante vulneración de derechos o desidia en atender su demanda.

\section{Mecanismos jurídicos para establecer sanciones}

Para fijar criterios que permitan formular sanciones a los congresistas de la República por incumplimiento de los exhortos de la Corte Constitucional o del deber legislativo, se deben identificar los mecanismos jurídicos viables que permitan establecer penas o sanciones en contra de los servidores públicos a la luz del ordenamiento jurídico colombiano, estos serían:

1.Asamblea Nacional Constituyente: Es una reunión nacional de diferentes representantes del pueblo que tiene como finalidad especificar reglas o parámetros para crear una nueva norma fundamental o Constitución que permitirá regir la relación, organización y regulación de los gobernantes con los gobernados, creando el sustento deóntico del sistema político y social, conocido como el poder constituyente.

La conformación de una Asamblea Nacional Constituyente sería una de las medidas más drásticas a presentarse, pero en caso tal de realizarse por este o algún otro motivo de trascendencia nacional, sería pertinente modificar y aumentar las sanciones a los congresistas por incumplimiento del deber legislativo, no solo las mencionadas de inhabilidades y pérdida de investidura, sino crear una nueva que sea más efectiva para ser expulsados de su cargo, como la revocatoria del mandato, que sólo se aplica a gobernantes del orden territorial o la moción de censura de los Ministros.

Así las cosas, la conformación de una Asamblea Nacional Constituyente implica un giro o cambio de paradigma a las disposiciones jurídicas establecidas desde hace 26 años en Colombia, por lo tanto, cabe cuestionarse qué tan conveniente sería volver a crear una y reflexionar si esa sería la solución más eficaz, lo cual se considera que no es la más idónea, ya que el problema no radica únicamente en cambiar uno o varios artículos constitucionales, sino en adoptar por un lado, una regulación jurídica que imponga sanciones efectivas y rigurosas a los congresistas, y por el otro, adoptar medidas para la descongestión legislativa en el Congreso de la República, que ahí es donde radica el verdadero problema.

2. Acto legislativo: Es un acto mediante el cual solo el Congreso de la República o el poder legislativo, puede reformar la Constitución Política, este se realiza a través de un procedimiento complejo, minucioso y con un control de constitucionalidad que examina los cargos por vicios de procedimiento toda vez que se discuten situaciones jurídicas que deben estar acordes a la esencia de la norma fundamental por ser una función constituyente. Es así como el artículo 375 de la Constitución señala que podrán presentar proyectos de acto legislativo el Gobierno, diez miembros del Congreso, el veinte por ciento de los concejales o de los diputados y los ciudadanos en un número equivalente al menos, al cinco por ciento del censo electoral vigente. El trámite de dicho proyecto tendrá lugar en dos períodos ordinarios y consecutivos. Aprobado en el primero de ellos por la mayoría 
de los asistentes, el proyecto será publicado por el Gobierno. En el segundo período la aprobación requerirá el voto de la mayoría de los miembros de cada Cámara.

Con base en lo anterior, un proyecto de acto legislativo que permita implementarle a las funciones del Congreso del artículo 150 de la Constitución Política el cumplimiento de los exhortos de la Corte Constitucional o por otro lado, agregar en las causales de inhabilidad (artículo 280) o de pérdida de investidura (artículo 296) una por incumplimiento del exhorto realizado por la Corte Constitucional. Con lo anterior sería posible establecer constitucionalmente el deber de acatar dichas sugerencias del Tribunal Constitucional y en caso de incumplimiento aplicar las sanciones políticas correspondientes, con lo cual se podría lograr mayor agilidad u organización para suplir los vacíos legislativos.

3. Referendo: Es un mecanismo de participación ciudadana mediante la cual se somete a voto popular aprobar o rechazar reformas constitucionales, proyecto de norma jurídica o derogar normas vigentes. Se encuentra regulado en la Ley 134 de 1994 y en la Constitución Política en el artículo 377 el cual plasma que deberán someterse a referendo las reformas constitucionales aprobadas por el Congreso, cuando se refieran a los derechos reconocidos en el Capítulo 1 del Título II y a sus garantías, a los procedimientos de participación popular, o al Congreso, si así lo solicita, dentro de los seis meses siguientes a la promulgación del Acto Legislativo, un cinco por ciento de los ciudadanos que integren el censo electoral. La reforma se entenderá derogada por el voto negativo de la mayoría de los sufragantes, siempre que en la votación hubiere participado al menos la cuarta parte del censo electoral. Igualmente, el artículo 378 consagra que por iniciativa del Gobierno o de los ciudadanos se podrá someter a referendo un proyecto de reforma constitucional que el mismo Congreso incorpore a la ley. El referendo será presentado de manera que los electores escojan libremente en el temario o articulado qué votan positivamente y qué votan negativamente.

En este orden de ideas, mediante un referendo podría proponer la reforma constitucional anteriormente mencionada, un número de ciudadanos igual o superior al cinco por ciento del censo elector de la fecha según lo establece el artículo 150 de la Constitución Política, dicha iniciativa será tramitada por el Congreso o proponerse un proyecto de ley que establezca medidas sancionatorias como el pago de multas o de otra carga social por el incumplimiento del deber legislativo por parte de los miembros de las comisiones del Congreso de la República.

4.Código de Ética o nuevo Estatuto del Congreso: Según el artículo 151 de la Constitución Política, el Congreso expedirá las leyes orgánicas que regularán el ejercicio de su actividad legislativa, estableciendo sus reglamentos, por lo tanto, si se presentara nuevamente un proyecto de ley orgánica por parte de los congresistas sobre un Estatuto de Ética como en otros países o actualizar el que tienen, estableciendo sanciones políticas más estrictas como las mencionadas por inhabilidad o pérdida de investidura, procedimientos más estrictos, control y vigilancia de agentes externos, organización y prioridad entre los proyectos de ley, metas cronológicas e incentivos a las comisiones que cumplan con dichos objetivos, una nueva comisión encargada exclusivamente de temas de omisiones legislativas, capacitaciones sobre los tópicos de trascendencia, y otros aspectos, podría crearse conciencia e incentivarse la responsabilidad $\mathrm{y}$ deber que tienen estos funcionarios con la sociedad.

5. Inconstitucionalidad o Constitucionalidad condicionada de la Ley 5 de 1992: Otra medida sería, a través de vía de acción de 
constitucionalidad, solicitar la declaratoria de inexequibilidad de la ley orgánica por vulnerar los artículos constitucionales 13 (igualdad), 135 (facultades de cada cámara), 150 (funciones del Congreso) ya que al tener sanciones que no van acordes con el cumplimiento de las finalidades de los artículos constitucionales mencionados se vulneran derechos fundamentales de la sociedad y a su vez los principios de la función pública. Por otro lado, podría la Corte proferir un fallo de exequibilidad y exhorto, en la medida que dispusiera que el Congreso, para el cumplimiento de la efectiva laboral legislativa y a su vez para garantizar los derechos fundamentales protegidos por la Constitución para aquellos que se encuentran inmersos en una omisión legislativa, implemente en un plazo razonable sanciones disciplinarias para los miembros de las comisiones parlamentarias en el Estatuto del Congresoquenovayan en contravía delodispuesto en la Convención Interamericana de Derechos Humanos (Control de Convencionalidad); o, también puede existir la posibilidad de generarse un fallo de exequibilidad condicionada en el cual la Corte Constitucional fije los parámetros para reglamentar sanciones de índole política.

6. Demanda ante la el Sistema Interamericano de Derechos Humanos: Después de agotar todos los recursos internos, el último mecanismo sería acudir al Sistema Interamericano de Derechos Humanos para velar por la protección y realización de los derechos humanos siguiendo el procedimiento establecido por la Convención Americana, siendo esto así, se realizaría la petición necesaria o queja ante la Comisión Interamericana invocando la violación de los derechos producto de la omisión legislativa que existe en el país, posteriormente y después de ser analizada, podrían generarse las recomendaciones pertinentes que deberían ser acatadas por el órgano legislativo y en caso de no cumplirlas podría remitirse el asunto a la Corte Interamericana de Derechos Humanos. Con esta medida que sería la última ratio de la jurisdicción, podría generarse un llamado de atención para regular de manera eficaz y adecuada los temas que afectan a la sociedad

\section{Delimitación de criterios}

Partiendo de la base que los mecanismos jurídicos referidos en los acápites anteriores permiten establecer sanciones en contra de los congresistas, se deben delimitar aquellos criterios que servirán como base para la formulación, diseño, implementación y ejecución de dichas sanciones en el ordenamiento jurídico colombiano. Con base en lo anterior se proponen los siguientes criterios:

\section{Axiológico}

Este componente va relacionado con el cumplimiento de los valores, fines y principios del Estado Social de Derecho por parte de los integrantes de las ramas del poder público. La Constitución Política de 1991 señala en su preámbulo que la teleología del Estado es asegurar a sus integrantes la vida, libertad, convivencia e igualdad, entre otros, dentro de un marco jurídico que garantice un orden social justo. Siendo esto así, es menester que todos los organismos del Estado adopten medidas acordes con dicha axiología estatal para hacer valer los derechos consagrados en la norma fundamental.

En este sentido, el Congreso de la República al ser el órgano que representa por excelencia a la sociedad, debe dirigir sus actuaciones en satisfacer los intereses y necesidades de sus representados, por lo tanto, las funciones que tienen a cargo deberían desarrollarlas con una alta carga de responsabilidad, agilidad, eficacia y conocimiento para impulsar los objetivos establecidos en la Constitución. Su labor es una de las más importantes en el Estado, de ellos depende la producción de normas que rigen cada materia en el país, por lo cual un descuido, 
negligencia o desidia en su trabajo afecta no a una persona o grupo sino a todos los colombianos inmersos en la situación.

Así las cosas, en la medida en que los miembros del Congreso no enfoquen su labor y esfuerzo para beneficio de los intereses sociales, se seguirán produciendo vacíos normativos que terminan afectando el respeto de las garantías y derechos del pueblo y, sobre todo, la ruptura del principio de la igualdad, lo cual estaría en inobservancia del deber constitucional.

Teniendo en cuenta lo anterior, es necesario que los congresistas conozcan y retomen los valores constitucionales e institucionales por los cuales el pueblo luchó, para así establecer proyectos que permitan garantizar las finalidades del Estado Social de Derecho y proteger, en todos los aspectos jurídicos, a la sociedad que depende de su labor, finalmente ahí se encuentran también todos los que rodean familiar o emocionalmente a cada uno de los congresistas.

\section{Garantismo Constitucional}

La ideología jurídica del garantismo constitucional toma auge por las diferentes acepciones que le ha atribuido su máximo exponente, Luigi Ferrajoli; su noción principal tiene como foco precisamente la garantía, la cual es entendida como "cualquier técnica normativa de tutela de un derecho subjetivo, entendiendo por 'derecho subjetivo' toda expectativa jurídica positiva (de prestaciones) o negativa (de no lesiones)" (Ferrajoli, 2011, p. 3)

A partir de la promulgación de la Constitución de 1991, Colombia transformó su antiguo paradigma de Estado de Derecho en uno donde se implementó la constitucionalización del derecho, adoptando ciertos puntos de la filosofía del garantismo, sobre todo en lo que se refiere a la permeabilidad que tiene la norma fundamental en todo el ordenamiento jurídico, y los mecanismos, medios o acciones constitucionales para hacer valer las disposiciones contenidas en la norma fundamental. A su vez, la Constitución colombiana ha sido desarrollada e interpretada normativa y jurisprudencialmente por los órganos competentes para darle el carácter vinculante que en la actualidad posee, por lo tanto, es norma de normas y de obligatorio cumplimiento, todo lo que sea incompatible con ella deberá ser expulsado del ordenamiento jurídico.

Con base en lo anterior, el activismo judicial ejercido por la Corte Constitucional ha permitido ampliar e interpretar las garantías constitucionales motivando su decisión (ratio decidendi) en la eficacia que deberían tener las disposiciones normativas con lo establecido por la Constitución. Como consecuencia, se han proferido cantidad de sentencias moduladas con la finalidad de promover la seguridad jurídica y reconocer los derechos de los afectados, y en caso de considerarse incompetente, ha exhortado al órgano legislativo a garantizar, mediante la expedición de norma, aquellos derechos que no se han desarrollado, por lo tanto, también es deber del Congreso adaptar la realidad social al modelo normativo actual con el objetivo de desarrollar lo establecido constitucionalmente.

Como corolario, este componente incluye la responsabilidad que tiene el Congreso de la República de legislar en virtud de la obligación emanada por la Constitución de expedir normas efectivas y adecuadas al desarrollo social que puedan ser invocadas ante la jurisdicción para su cumplimiento y tutela, más no, como en la actualidad, para su reconocimiento precoz e insuficiente.

\section{Positivista estricto}

El iuspositivismo es la corriente jurídica definida como "El conjunto de normas puesta por los seres humanos, a través del Estado, mediante un procedimiento formalmente válido, con la 
intención o voluntad de someter la conducta humana al orden disciplinario por el acatamiento de esas normas" (Cisneros, 2000, p.24).

Partiendo de la teoría desarrollada por Von Liszt (1980, p.51) sobre el positivismo criminológico italiano, donde se aplica el correccionalismo y la intimidación como finalidad preventiva para que el futuro autor de la conducta punible evite la comisión o reincidencia en la misma, es posible representar esta posición en la creación de sanciones más estrictas para los congresistas de la República plasmadas en el Código Penal , específicamente en el Titulo XV "Delitos contra la Administración Pública", tales como penas de prisión más altas, multas cuantiosas e inhabilidades expresas, trabajos a la comunidad, entre otros.

Para que este iuspositivismo sea estricto, adicional de estipular en la norma sanciones más severas, se debe complementar, primero, con la eficacia y correcta aplicación de las penas por parte de los servidores judiciales encargados de juzgar a estos funcionarios aforados y segundo, con la vigilancia en su cumplimiento por parte de un Juez de Ejecución de Penas o un comité especial. A su vez, sería necesaria la presentación de informes a la comunidad y al Congreso de la República sobre los procesos relacionados por incumplimiento del deber legislativo de los congresistas y de las condenas proferidas por parte de la Corte Suprema de Justicia en su función investigativa y de juzgamiento para estos casos.

En resumen, y teniendo en cuenta que Colombia es un Estado fiel a la materialización del derecho mediante normas y códigos, a través de este criterio, se pretende incentivar la creación de sanciones jurídicas en el Código Penal o cualquier otra ley que sean ejemplarizantes para la sociedad y para quienes en un futuro aspiren al cargo de congresista.

\section{Criterios de priorización y capacitación legislativa}

Si bien es cierto que la Ley 5 de 1992 establece que cada una de las Cámaras se organizarán por comisiones constitucionales permanentes, legales, especiales y accidentales que tramitarán y darán debate a los proyectos de ley o actos legislativos relacionados con los asuntos de su competencia, dicha distribución no ha permitido la regulación de determinados asuntos trascendentales para la sociedad tales como el matrimonio homosexual, transexualidad, alquiler de vientre, eutanasia, entre otros.

Las funciones $\mathrm{y}$ composición de dichas comisiones están reguladas en la Ley $3^{\mathrm{a}}$ de 1992, cada comisión tiene un tema específico asignado para tramitarlo, debatirlo, estudiarlo, y finalmente expedir la correspondiente norma, a su vez la Constitución dispone en el artículo 152, que debería darse prioridad a las leyes estatutarias (derechos y deberes fundamentales de las personas y los procedimientos y recursos para su protección, administración de justicia; organización y régimen de los partidos y movimientos políticos; estatuto de la oposición y funciones electorales; instituciones y mecanismos de participación ciudadana; estados de excepción; e igualdad electoral entre los candidatos a la Presidencia de la República que reúnan los requisitos que determine la Ley) y proyectos de ley aprobatorios en materia de derechos humanos.

De este modo, la Ley $3^{\mathrm{a}}$ de 1992 permite evidenciar que las comisiones del Congreso de la República tienen asuntos delimitados para debatir y ciertos temas son más urgentes que otros en la agenda legislativa. Sin embargo, en ninguna comisión, ni en la Constitución o en la referida ley, se establece la importancia de categorizar prioritariamente aquellos temas exhortados al Congreso por la Corte Constitucional. Por tal motivo, estos asuntos terminan legislándose 
dilatoriamente o en un largo período por no darles la importancia que corresponde.

Por consiguiente, este criterio se enfoca en instaurar dentro de la organización interna del Congreso 4 puntos:

- Establecer un orden de prioridad para los diferentes tipos de leyes a expedir, incluyendo los exhortos elaborados por la Corte Constitucional que deberán ser repartidos a las comisiones pertinentes integrándose entre los primeros puntos de la agenda a tratar.

- Como consecuencia de lo anterior, crear y organizar un sistema cronológico para las diferentes clases de leyes, en el cual se delimitaría un tiempo razonable para expedir la normatividad pertinente, imponiendo sanciones bien sean pecuniarias o disciplinarias en caso de demora injustificada y generando incentivos a las comisiones más eficientes.

- Para obtener resultados efectivos en los debates legislativos, abrir convocatorias en conjunto con Colciencias para determinar los puntos vulnerables, propuestas, análisis, entre otros aspectos, de grupos académicos o sectores poblacionales que permitan mejorar la actividad legislativa, creando incentivos académicos para los mejores proyectos.

- Capacitaciones periódicas a los miembros del Congreso de la República que les permita tener mayor conocimiento sobre los temas que están debatiendo para generar buenas propuestas que no prevean todas las situaciones y solucionen cualquier problemática social. Estas pueden ser solicitadas por los mismos congresistas o existir determinados horarios mensuales, y en caso inasistencia injustificada se generarían descuentos en sus salarios o si reincidieren en faltar, causal de futura inhabilidad.
De conformidad con lo precedente, sería posible tener una mejor organización y funcionamiento de las comisiones del Congreso en cuanto a la legislación que deben expedir anualmente en las diversas materias, así mismo a través de estos parámetros se podría involucrar a la sociedad civil a que exponga o proponga aspectos relacionados con la omisión o la situación en que se encuentran para que los congresistas junto con sus capacitaciones tengan un mayor radio de acción y conocimiento del asunto que van a desarrollar, so pena de ser sancionados por su ineficacia e inasistencia en los debates legislativos.

\section{Participación ciudadana}

La sociedad civil puede participar en la vigilancia del cumplimiento de las funciones que ejercen los miembros del Congreso de la República, puesto que al ser el pueblo quien los eligió también puede ejercer las acciones pertinentes para que cumplan y rindan cuentas sobre lo realizado en su periodo legislativo.

Los siguientes son los medios que principalmente tienen la sociedad para ejercer dicha vigilancia: en primer lugar, el mecanismo democrático de representación establecido por la Ley 850 de 2003 acerca de las veedurías ciudadanas. Esta norma establece que se entiende por Veeduría Ciudadana el mecanismo democrático de representación que le permite a los ciudadanos o a las diferentes organizaciones comunitarias, ejercer vigilancia sobre la gestión pública, respecto a las autoridades administrativas, políticas, judiciales, electorales, legislativas y órganos de control, así como de las entidades públicas o privadas, organizaciones no gubernamentales de carácter nacional o internacional que operen en el país, encargadas de la ejecución de un programa, proyecto, contrato o de la prestación de un servicio público. 
Es así como las veedurías podrán elevar ante las autoridades competentes derechos de petición, y ejercer ante los jueces de la República todas las acciones que siendo pertinentes consagran la Constitución y la ley para lograr de manera ágil y oportuna el cumplimiento de las actividades y la buena gestión de los funcionarios del Estado. De igual forma, las veedurías podrán intervenir en audiencias públicas; denunciar ante las autoridades competentes las actuaciones, hechos y omisiones de los servidores públicos y de los particulares que ejerzan funciones públicas, que constituyan delitos, contravenciones, irregularidades $o$ faltas en materia de contratación estatal y en general en el ejercicio de funciones administrativas o en la prestación de servicios públicos; utilizar los demás recursos, procedimientos e instrumentos que leyes especiales consagren para tal efecto; y solicitar a la Contraloría General de la República, mediante oficio, el control excepcional establecido en el artículo 26, literal b) de la Ley 42 de 1993: “La Contraloría General de la República podrá ejercer control posterior, en forma excepcional, sobre las cuentas de cualquier entidad territorial, sin perjuicio del control que les corresponde a las contralorías departamentales, y municipales).

Con relación a lo anterior, la responsabilidad que tienen las veedurías en la gestión pública se fundamenta en el principio de colaboración que tienen los particulares con las instituciones del Estado para el efectivo cumplimiento de sus fines, así mismo, es un mecanismo en que la ciudadanía puede participar y manifestarse legalmente en asuntos que le afectan a todos, por ejemplo, la malversación y el destino del dinero de los impuestos que se pagan que en muchas ocasiones no se ven retribuidos a los intereses públicos, así la sociedad se convierte en un sujeto activo dentro del modelo de la administración pública y presiona para que el órgano legislativo desarrolle en su normatividad disposiciones que permitan el beneficio de la mayoría y no de unos pocos.
En segundo lugar, la Constitución establece en su artículo 184 la figura de la pérdida de investidura como sanción política para los congresistas, la cual puede ser a petición de la Cámara correspondiente o cualquier ciudadano ante el Consejo de Estado. Este es un procedimiento el cual cesa del mandato a uno o varios congresistas por haber incurrido en las causales establecidas en la norma por no ser merecedoras de representar los intereses de la sociedad, es así como la pérdida de investidura se convierte en un medio de control parlamentario que tiene la ciudadanía pero que es poco ejercido y conocido, pero de gran importancia constitucional.

No obstante, es una figura que presenta muchas dificultades para los integrantes del Consejo de Estado a la hora de aplicarla por las discrepancias que se tienen al momento de emitir la decisión. Aunado a lo anterior, se encuentra la politización de la justicia administrativa que actualmente se presenta y por la cual muchos procesos se archivan. Por estas razones, se hace necesario un control más estricto desde la jurisdicción contenciosa administrativa instaurando una sala transitoria para conocer de esta acción de pérdida de investidura, o un conjunto de conjueces para dirimir estos casos, o en última medida, un control difuso, con la finalidad de hacer más efectivo el uso y funcionamiento de esta significativa sanción política.

Por último, los ciudadanos pueden acudir ante la Corte Constitucional a través de la acción pública de inconstitucionalidad con la finalidad de impugnar la constitucionalidad de los actos señalados en el artículo 241 de la Constitución Política.

El Decreto 2067 de 1991 determina que esta acción pública puede incoarse por cualquier ciudadano en defensa del interés público en cualquier tiempo excepto en los casos de vicios de forma que su caducidad es de un año desde la publicación. 
Mediante la acción anterior, los ciudadanos pueden hacer valer sus derechos o poner en conocimiento de la Corte Constitucional una omisión legislativa con el objetivo de que, a través de la sentencia, con efectos erga omnes, se profiera un fallo modulado o se exhorte al Congreso de la República a que intervenga regulando y desarrollando normativamente determinada materia que posiblemente no tenían en su agenda legislativa.

\section{Conclusiones}

El tratamiento que realiza la Corte Constitucional colombiana en los casos donde se presentan omisiones legislativas, a través de la tipología especial de sus sentencias (manipulativas y exhortativas), solo procede cuando estas son de carácter relativo, puesto que, cuando el legislador expide una norma, excluye ciertos supuestos de hecho o grupos de personas generando un estado de inseguridad jurídica para las mismas, lo cual permite al Tribunal Constitucional realizar el contraste de la norma invocada con las disposiciones constitucionales vulneradas.

En los casos de omisiones legislativas absolutas que se presentan cuando el legislador no desarrolla formal y materialmente una situación jurídica establecida por obligación de la norma fundamental, la Corte Constitucional no es competente para pronunciarse por no poder llevar a cabo el respectivo control de constitucionalidad por ausencia de norma. Sin embargo, para no inmiscuirse en la función legislativa y respetar el principio de la división de poderes, ha optado por exhortar al Congreso de la República para que en un tiempo prudencial desarrolle el tema que se examinó en la sentencia.

Del estudio de diez sentencias hito, a luz de algunos de los exhortos que ha realizado la Corte Constitucional de Colombia al Congreso de la República desde 1997 hasta la actualidad, se pudo evidenciar que en seis de diez casos, el órgano legislativo no ha expedido una normatividad que desarrolle el tema, retardando la actividad legislativa en un periodo de 1 a 18 años. No obstante, en las cuatro situaciones en que se presentaron omisiones relativas, la Corte Constitucional, mediante una sentencia manipulativa, solucionó de inmediato el problema generado por el vacío normativo, supliendo y garantizando la protección de los derechos constitucionales en cuestión.

Al identificar las diferentes normatividades que contenían sanciones para los miembros del Congreso de la República, tales como, la Constitución Política, el Acto Legislativo 10 de 2009, Ley 5 de 1992, el Código Único Disciplinario y algunos proyectos de Ley, fue posible observar que estos, eran en su mayoría, de carácter disciplinario, fiscal, penal o dirigidos al partido político; sanciones que en ningún momento se configuraban por incumplimiento de los exhortos proferidos por la Corte Constitucional o por la deficiencia del deber legislativo, sino por faltas injustificadas a las sesiones, prohibiciones, incompatibilidades, inhabilidades, pérdida de investidura, aval de candidatos, entre otros, lo que permite entender por qué en el Congreso de la República existe un constante estado de inmunidad ante la ineficiencia e insuficiencia del órgano legislativo.

La ausencia de medidas sancionatorias para los miembros del Congreso de la República por incumplimiento de los exhortos proferidos por la Corte Constitucional genera violaciones a los derechos fundamentales a causa de las omisiones legislativas, las cuales si no son desarrolladas por el único que es competente, desencadenan en un estado de incertidumbre jurídica que transgrede uno de los principales pilares del Estado de Social de derecho, la igualdad; en consecuencia desemboca un conflicto socio-jurídico que es necesario regular y desarrollar para armonizar la normatividad con el espíritu y contenido de la Constitución. 
Como opciones jurídicamente viables, en algunos casos, para sancionar a los congresistas por incumplimiento del exhorto de la Corte Constitucional se referenciaron las siguientes: en primer lugar, la posibilidad de adoptar actos legislativos como solución más idónea; en segundo lugar, la formación de una Asamblea Nacional Constituyente para modificar la Constitución, situación que puede resultar inviable por el engorroso y demorado proceso que implica la formación y desarrollo de la misma en tercer lugar, la convocatoria a un referendo, pero, esta es una figura que implica tiempo y planeación siendo también de difícil aplicación; en cuarto lugar, la adición de una causal en la figura ya regulada de la pérdida de investidura; en quinto lugar, la declaratoria de inexequibilidad o exequibilidad condicionada de la Ley 5 de 1992 (Estatuto del Congreso) que requiere urgentemente una actualización por ser una de las normas más vinculantes para el órgano legislativo y como última instancia, una petición ante la Comisión Interamericana de Derechos Humanos por su pertinencia y fuerza vinculante en el ordenamiento jurídico, aunque también implica un trámite extenso para su cumplimiento.

Se plantea que exista una mejor organización dentro de la institución para priorizar y delimitar cronológicamente las materias a legislar, apoyándose en capacitaciones, preparación profesional y mediante grupos académicos o socialesque conocenmejorlasnecesidades decada sector, incentivando así la actividad legislativa a través de estímulos por el cumplimiento de los objetivos planteados en un tiempo razonable, so pena de imponer, las correspondientes sanciones pecuniarias o disciplinarias en caso de demora o falta injustificada a las sesiones del Congreso. Así mismo, se requiere de mayor conocimiento y participación ciudadana para ejercer el control y vigilancia de la gestión pública ejercida por el Congreso de la República y hacer valer los derechos que por ley les corresponden, a través de los diferentes mecanismos que permiten generar peticiones o dar inicio a determinadas acciones, tales como, la pública de inconstitucionalidad, la petición de pérdida de investidura o la acción ejercida por las veedurías ciudadanas, para efectos de presionar al órgano legislativo a asistir a las sesiones, cumplir con sus funciones y a expedir adecuada y suficientemente la normatividad acorde con las condiciones sociales de la época.

Los criterios base para establecer una sanción y materializarla, mediante los mecanismos jurídicos mencionados, podrían contener uno o varios de los aspectos tratados: axiológicos (aspecto dogmático, valores, principios, fines), garantistas (acciones que deben adoptar las ramas del poder en cuanto a concretar y tutelar los bienes y valores que están vigentes en el modelo normativo), positivistas (strictu sensu), priorización y capacitación legislativa o participación ciudadana. La aplicación de alguno de los anteriores parámetros permitiría fundamentar y motivar una norma, disposición legislativa o constitucional que imponga cualquier tipo de sanción a los miembros del legislativo en caso de incumplimiento del deber, especialmente, cuando de exhortos se refiere; no obstante, también es importante, que una vez expedida la normatividad o disposición sancionatoria tenga un riguroso y minucioso proceso de seguimiento y vigilancia periódica para obtener efectivos y verdaderos resultados reflejados en el ordenamiento jurídico y en el beneficio de la sociedad.

\section{Referencias bibliográficas}

Acto Legislativo 01 de 2009, por el cual se modifican y adicionan unos artículos de la Constitución Política (14 de julio). Diario Oficial n ${ }^{\circ} 47.410$

Auto 078 de 2013 (abril 24). M.P. Luis Ernesto Vargas Silva 
Baustista, M. (13 de agosto de 2014). El mediador; otra de las facetas de Jaime Garzón. El Tiempo, recuperado de http://www.eltiempo.com/archivo/ documento/CMS-14375977

Centro Democrático. (19 de agosto de 2015). Exposición de motivos al proyecto de ley "por medio del cual se endurecen las sanciones para la inasistencia de los congresistas y funcionarios". Recuperado de: http:// http://www. centrodemocratico.com/sites/default/ files/wp-content/uploads/2015/08/PROYECTO-DE-LEY-CONTRA-AUSENTISMO-PARLAMENTARIO.pdf

Constitución Política de 1991 (4 de julio)

Decreto No. 1320 de 1998 (julio 15), Por el cual se reglamenta la consulta previa con las comunidades indígenas y negras para la explotación de los recursos naturales dentro de su territorio. Diario Oficial $\mathrm{n}^{\circ}$ 43.340

Ferrajoli, L., \& de la Vega, A. D. C. (2007). Sobre los derechos fundamentales y sus garantias. Cndh.

Garay, Kennier J. (2014) Las modulaciones de contenido o sentencias manipulativas en la Corte Constitucional colombiana. Una tipología mediada por la distinción entre enunciado normativo y norma. Recuperado de http://tesis.udea. edu.co/bitstream/10495/3762/1/ GarayKennier_2014_modulacionescontenidosentenciasmanipulativas.pdf

García, E.(1989). Filosofia del Derecho. Ciudad de México. Porrúa.

Ley 5 de junio de 1992 (18 de junio), por la cual se expide el Reglamento del Congreso; el Senado y la Cámara de Representantes . Diario Oficial n $\mathrm{n}^{\mathrm{H}} 40.483$
Ley 599 de 2000 ( 24 de julio), por la cual se expide el Código Penal. Diario Oficial $\mathrm{n}^{\circ} 44.097$

Ley 734 de 2002 (5 de febrero), por la cual se expide el Código Disciplinario Único. Diario Oficial n ${ }^{\circ} 44.699$

Proyecto de Ley 200 de 2013 (febrero 25), por medio de la cual se expide el Código de Ética y Disciplinario del Congresista y se dictan otras disposiciones.

Nogueira, H (2009) El derecho procesal constitucional a inicios del siglo XXI en América Latina. Revista estudios constitucionales, 7(1), 13-58.

Olano, H.. (2004). Tipología de nuestras sentencias constitucionales. Vniversitas, 53(108), 571-602

Proyecto de Ley 202 de 2016 (marzo 9), por medio de la cual se prohíbe la práctica de la maternidad subrogada al ser una categoría de trata de personas y explotación de la mujer con fines reproductivos.

Resolución 415 de 2010 (abril 13), Por la cual se expide el Reglamento de Radiodifusión Sonora y se dictan otras disposiciones.

Resolución 1216 de 2015 (abril 20), por medio de la cual se da cumplimiento a la orden cuarta de la sentencia T 970 de 2014 de la Honorable Corte Constitucional en relación con las directrices para la organización y funcionamiento de los Comités para hacer efectivo el derecho a morir con dignidad.

Corte Constitucional de Colombia - Sentencia C 113 de 1993 (marzo 25). M.P. Jorge Arango Mejía 
Corte Constitucional de Colombia - Sentencia C 543 de 1996 (octubre 16). M. P. Carlos Gaviria Díaz..

Corte Constitucional de Colombia - Sentencia C 239 de 1997 (mayo 20). M.P. Carlos Gaviria Díaz.

Corte Constitucional de Colombia - Sentencia C 355 de 2006 ( mayo 10) M.P. Jaime Araújo Rentería y Clara Inés Vargas Hernández

Corte Constitucional de Colombia - Sentencia T 968 de 2009 (diciembre 18) .M.P. María Victoria Calle Correa.

Corte Constitucional de Colombia - Sentencia C 442 de 2009 (julio 8). M.P. Humberto Antonio Sierra Porto

Corte Constitucional de Colombia - Sentencia C 577 de 2011 (julio 26). M.P. Gabriel Eduardo Mendoza Martelo

Corte Constitucional de Colombia - Sentencia T 129 de 2011 (marzo 3). M.P. Jorge Iván Palacio Palacio.

Corte Constitucional de Colombia - Sentencia C 818 de 2011 (noviembre 1). M.P. Jorge Ignacio Pretelt Chaljub

Corte Constitucional de Colombia - Sentencia C 359 de 2013 (junio 26). M.P. Jorge Iván Palacio Palacio.

Corte Constitucional de Colombia - Sentencia T 970 de 2014 (diciembre 15) M.P. Luis Ernesto Vargas Silva.

Corte Constitucional de Colombia - Sentencia T 099 de 2015 (marzo 10) M.P. Gloria Stella Ortiz Delgado.

Corte Constitucional de Colombia - Sentencia C 291 de 2015 (mayo 20). M.P. Gloria Stella Ortiz Delgado.
Corte Constitucional de Colombia - Sentencia C 683 de 2015 (noviembre 4) M.P.. Jorge Iván Palacio Palacio

Corte Constitucional de Colombia - Sentencia SU 214 de 2016 (abril 28). M.P. Alberto Rojas Rios

Corte Constitucional de Colombia - Sentencia C 005 de 2017 (enero 18). M.P. Luis Ernesto Vargas Silva

Transparencia por Colombia (2009). Sobre la transparencia en la gestión pública. Recuperado https://www.medellin. gov.co $/ \mathrm{irj} / \mathrm{go} / \mathrm{km} /$ docs/enconfianza/ articulosytemas/documentos/ Transparencia\%20en $\% 201$ a $\% 20$ Gestión\%20Pública.pdf 